\title{
High Performance Conducting Nanocomposites Polyaniline (PANI)-CuO with Enhanced Antimicrobial Activity for Biomedical Applications
}

\author{
Supriya Vyas, ${ }^{1, *}$ Ashutosh Shukla, ${ }^{1}$ Sugam J Shivhare,${ }^{2}$ Vivekanand S Bagal ${ }^{2}$ and Navneeta Upadhyay ${ }^{1}$
}

\begin{abstract}
The purpose of this research is to develop advanced conducting material blended with metal oxides that held both conducting and antimicrobial properties and due to this, applicable in many biomedical fields. The synthesis of nanoparticles of copper oxide $(\mathrm{CuO})$ is performed by the chemical co-precipitation method and the synthesis of pure polyaniline (PANI) and PANI-CuO nanocomposites were performed by using in-situ chemical oxidative synthesis. The structural analysis was carried out by Xray diffraction (XRD) studies, Fourier transforms infrared spectroscopy (FTIR), and Ultraviolet-Visible (UV-Vis) absorption spectrometry. The peaks obtained in spectra validate the fabrication of desired materials. The average particle size of synthesized materials was calculated using the Debye Scherrer formula, which was found in the nanoscale range. The scanning electron microscope (SEM) images explored the morphology of CUO and PANI-CUO composite. The direct current (DC) conductivity measurement of samples was performed by the four-probe method for various temperatures. The values showed an increase of electrical conductivity in the composite as compared to PANI and supported the metallic nature of the composite. The antibacterial activity of composites was performed by disk diffusion method using Bacillus subtilis (Gram + ve bacteria) and Escherichia coli (Gram-ve bacteria) and the results are encouraging.
\end{abstract}

Keywords: Conjugated conducting polymers; Co-precipitation method; Ammonium persulphate; Debye Scherrer formula. Received date: 17 Feb 2021; Accepted date: 11 May 2021.

Article type: Research article.

\section{Introduction}

Intrinsically conducting polymers (ICPs) is an expanding field in material science due to the interesting electrical and optical properties of these polymers. A key requirement for a polymer to become intrinsically electrical conducting is that there should be an overlap of molecular orbitals to allow the formation of the delocalized molecular wave function. Besides this, for the free movement of electrons throughout the lattice, molecular orbitals must be partially filled. ${ }^{[1]}$ Pure polyaniline (PANI) is presently a very recognizable polymer among the conducting polymer because of its unique properties and its applications, good environmental stability, ease to synthesis, and low cost. ${ }^{[2]}$ PANI is a typical phenylene-based polymer having a chemically flexible-NH group in a polymer chain flanked on either side by a phenylene ring. It can also be

\footnotetext{
1 Department of Chemistry, Shri Vaishnav Vidyapeeth Vishwavidyalay, Indore (M.P.), India, 453111.

${ }^{2}$ Department of Applied Science and Humanities, SVKM's, NMIMS, Shirpur, (Maharashtra), India, 425405.

*E-mail: supriyavyas2012@gmail.com (S. Vyas)
}

defined as the simple 1, 4- coupling product of a monomeric aniline molecule. ${ }^{[3]}$ PANI shows an electrically conducting nature on doping with acid in its emeraldine oxidation state. The conductivity of PANI increases reversibly with doping from the undoped insulating base form $\left(\sigma \geq 10^{-10} \mathrm{~S} / \mathrm{cm}\right)$ to the fully doped, conducting salt form $(\sigma \leq 1 \mathrm{~S} / \mathrm{cm}) \cdot{ }^{[4]}$

Over some flaws including chemical swelling, shrinkage, solubility, and weak mechanical properties, the various applications of PANI may decrease. Organic polymeric materials, whenever exposed to various environmental conditions get degraded. By controlling the morphology and chemical modification in polymeric materials, stability and life enhancement can be achieved. ${ }^{[5]}$ Metal oxide dispersed polymer composites exhibit unexpected hybrid properties synergistically derived from both components. ${ }^{[6]} \mathrm{CuO}$ has a monoclinic structure and it is a semiconducting compound. ${ }^{[7]}$ $\mathrm{CuO}$ behaves like a p-type semiconductor because of the small energy difference between the valence and conduction bands. ${ }^{[8]}$ This semiconducting behavior of $\mathrm{CuO}$ makes $\mathrm{CuO}$ - PANI nanocomposites applicable in sensors, ${ }^{[9]}$ catalysts, batteries, supercapacitors, ${ }^{[10]}$ solar cells, and antibacterial ${ }^{[11]}$ applications. 
The $\mathrm{CuO}$ nanocomposites with PANI show much lower charge transfer resistance and better cyclic performance than nanoparticles of $\mathrm{CuO}^{\left[{ }^{[12]}\right.}$ The orthorhombic structure of PANI$\mathrm{CuO}$ nanocomposites shows metal-like properties. ${ }^{[13]}$ So, it can also be applicable as shielding and absorbing materials in microwave frequencies.

The development of materials that can minimize or prevent infectious microbial colonization is an urgent requirement to reduce diseases that affect public health and global economies. ${ }^{[14]}$ The potential of copper oxide nanoparticles in the field of medicine has been explored as an antioxidant and antimicrobial agent. ${ }^{[15,16]}$ Copper oxide nanoparticles are capable to kill a range of infection-causing bacterial pathogens. The $\mathrm{CuO}$ nanoparticles embedded in the PANI matrix also proved to have good antimicrobial activity. ${ }^{[17]}$

In the present study $\mathrm{CuO}$ nanoparticles, PANI, and nanocomposites of PANI-CuO were synthesized using in-situ chemical oxidative polymerization. The structure and morphology of synthesized materials were characterized by Xray diffraction (XRD), Fourier Transform Infrared spectroscopy (FTIR), UV Visible absorption spectrometry, and scanning electron microscopy (SEM). Additionally, the conductivity of pure PANI, CuO nanocomposites, and PANI$\mathrm{CuO}$ nanoparticles was measured by the four-probe technique. The Kirby-Bauer disc diffusion test method was used to determine the antibacterial properties due to their ability to release ions rather than their unique size-dependent properties.

\section{Experimental}

\subsection{Materials and methods}

\subsubsection{Materials}

Copper (II) nitrate, ammonia, aniline, ammonium persulphate, hydrochloric acid, ethanol, and acetic acid were purchased from Merck. All chemicals were high-grade reagents and were used as received.

\subsubsection{Synthesis of $\mathrm{CuO}$ nanoparticles}

The synthesis of $\mathrm{CuO}$ nanoparticles was carried out by the chemical co-precipitation method. 0.2 M Copper (II) nitrate solution was prepared in double distilled water. Copper hydroxide gel was formed on dropwise addition of ammonia in that copper (II) nitrate solution which was continuously stirred for 8 hours at $85^{\circ} \mathrm{C}$. The black shiny $\mathrm{CuO}$ crystals thus obtained were washed with distilled water and ethanol then filtered and dried in the oven.

\subsubsection{Synthesis of pure PANI}

PANI was fabricated by using the method of oxidative polymerization of aniline. In this method, two types of solutions were prepared. (a) $0.2 \mathrm{M}$ aniline solution in $100 \mathrm{ml}$ $1 \mathrm{M} \mathrm{HCl}$. (b) $0.2 \mathrm{M}$ ammonium persulphate solution in $50 \mathrm{ml}$ distilled water. The oxidant-based solution was added to the aniline-based solution dropwise with constant stirring on a magnetic stirrer at $0{ }^{\circ} \mathrm{C}$. The solution turned green from colorless. Now, the solution was further stirred for 6 hours using a magnetic stirrer at $5{ }^{\circ} \mathrm{C}$ temperature and placed in a refrigerator for 18 hours. The green precipitates were washed with distilled water to remove impurities and acetone to remove short-chain molecules of aniline which were soluble in acetone. The synthesized green material was dried in the oven at $80^{\circ} \mathrm{C}$ and ground in fine powder using a mortar and pestle.

\subsubsection{Synthesis of PANI-CuO nanocomposites}

The nanocomposites of PANI and $\mathrm{CuO}$ nanoparticles were amalgamated by an in-situ chemical oxidative polymerization process using $\mathrm{HCl}$ as a dopant and ammonium persulphate as an oxidant. In this process, $0.2 \mathrm{M}$ aniline solution was prepared in $100 \mathrm{ml} 1 \mathrm{M} \mathrm{HCl}$. In this aniline monomer solution known weight of $\mathrm{CuO}$ nanoparticles was added and stirred the solution in an ice bath for half an hour. $50 \mathrm{ml} 0.2 \mathrm{M}$ ammonium persulphate solution was dropwise added to the above solution and stirred at low temperature. Now, the solution was further stirred for 6 hours using a magnetic stirrer at the same temperature. The product formed was washed with acetone and distilled water and dried in an oven at $80^{\circ} \mathrm{C}$.

\subsection{Characterization}

The structural information of synthesized materials was recorded by using XRD studies, FTIR spectroscopy, and UVVIS spectroscopy. The morphological Studies were performed by SEM. Conductivity was measured by using four probe techniques and antibacterial activity was evaluated by the disk diffusion method.

Powder X-ray diffraction (XRD) patterns were recorded on Bruker's model D8 advance system using nickel-filtered $\mathrm{Cu}$ $\mathrm{K} \alpha$ radiation as the $\mathrm{x}$-rays source $(\lambda=1.54178 \AA)$. The measurement of the average particle size of synthesized materials was carried out by using the Debye-Scherrer formula. The FTIR spectra were recorded in the frequency range of 400-4000

$\mathrm{cm}^{-1}$ and the UV-Vis spectra were recorded in the wavelength range of $200-800 \mathrm{~nm}$. The morphological studies of materials were characterized by JEOL Scanning Electron Microscope equipped with an energy-dispersive X-ray spectrometer (EDAX). The four-probe conductivity measurement technique was used to calculate the DC conductivity of synthesized compounds. The antibacterial activity of fabricated PANI$\mathrm{CuO}$ nanocomposite was detected by disk diffusion method with concentrations of $5 \mathrm{mg} / \mathrm{ml}$ and $10 \mathrm{mg} / \mathrm{ml}$ against Bacillus subtilis (Gram-positive bacteria) and Escherichia coli (Gramnegative bacteria).

\section{Results and discussion \\ 3.1 X-ray diffraction (XRD) studies}

Figures 1 and 2 illustrate the XRD patterns of synthesized pure PANI, $\mathrm{CuO}$ nanoparticles, and polyaniline-CuO nanocomposites, respectively. Samples were step scanned in terms of $2 \theta$ in the range $20^{\circ}$ to $80^{\circ}$ angle. The pure PANI (Fig. 3) shows a diffraction peak of $2 \theta=17.09$ which can be 
attributed to the periodicity parallel and perpendicular to the polymer chain. ${ }^{[18]}$ The peak at $2 \theta=20.07^{\circ}$ is evidence of the characteristic distance between the ring planes of benzene rings in adjacent chains or close contact interchains. ${ }^{[19]}$ The peak centered at $2 \theta=24.92^{\circ}$ can be assigned to the scattering of PANI chains at an interplanar spacing which indicates that pure PANI has some degree of crystallinity. ${ }^{[20,21]}$ But less intense peaks support the amorphous nature of PANI.

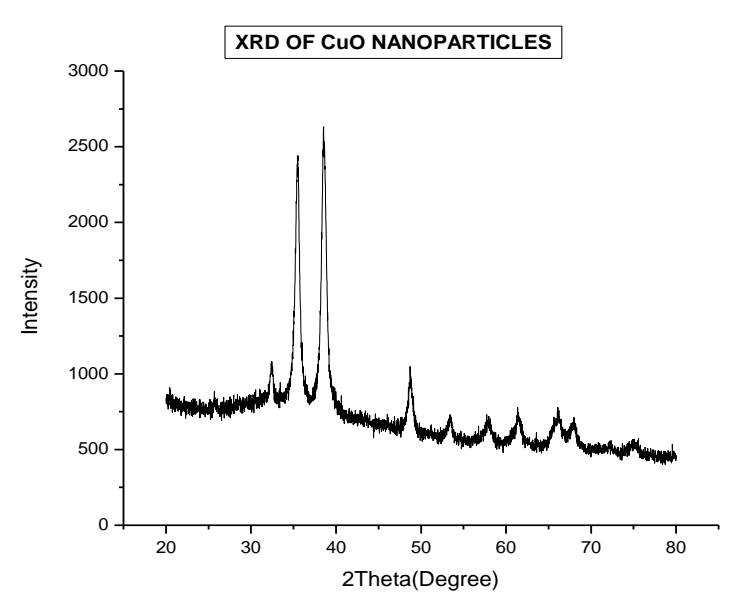

Fig. $1 \mathrm{X}$-ray diffraction pattern of $\mathrm{CuO}$ nanoparticles.

Figure 1 exhibits the XRD pattern of nanoparticles of $\mathrm{CuO}$ in which the sharp peaks indicate the high crystalline nature of nanoparticles. Sharp peaks are observed at $2 \theta=35.6^{\circ}$ and $38.7^{\circ}$ small peaks at $2 \theta=32.8^{\circ}, 48.6^{\circ}, 53.5^{\circ}, 58.5^{\circ}, 62.1^{\circ}, 66^{\circ}$ and $68^{\circ}$ which are in good agreement with the reported values (JCPDS card number 89-5899). It also confirms the monoclinic structure of $\mathrm{CuO}$ nanoparticles. The broad peaks indicate the nano-size effect.

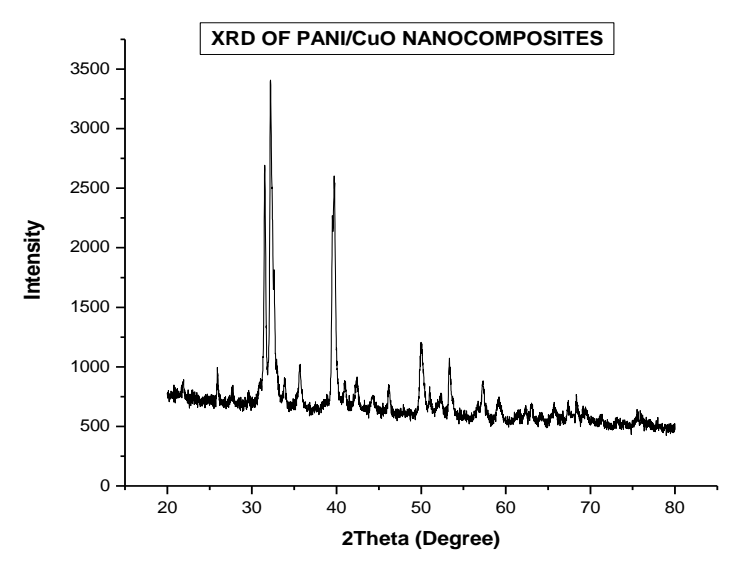

Fig. 2 X-Ray Diffraction pattern of PANI-CuO nanocomposite.

Figure 2 indicates the XRD pattern for PANI-CuO nanocomposites. The diffractogram of composite is showing peaks at $2 \theta=26.09^{\circ}, 31.8^{\circ}, 32.9^{\circ}, 35.7^{\circ}, 40^{\circ}, 50^{\circ}$ and $53.5^{\circ}$. The peak observed at $2 \theta=26.09^{\circ}$ resembles pure PANI and at $32.9^{\circ}, 35.7^{\circ}, 40^{\circ}, 50^{\circ}$, and $53.5^{\circ}$ to $\mathrm{CuO}$. The significant shift in positions of $2 \theta$ values confirms the formation of composites with some interactions between the PANI chain and nanoparticles of $\mathrm{CuO}$.

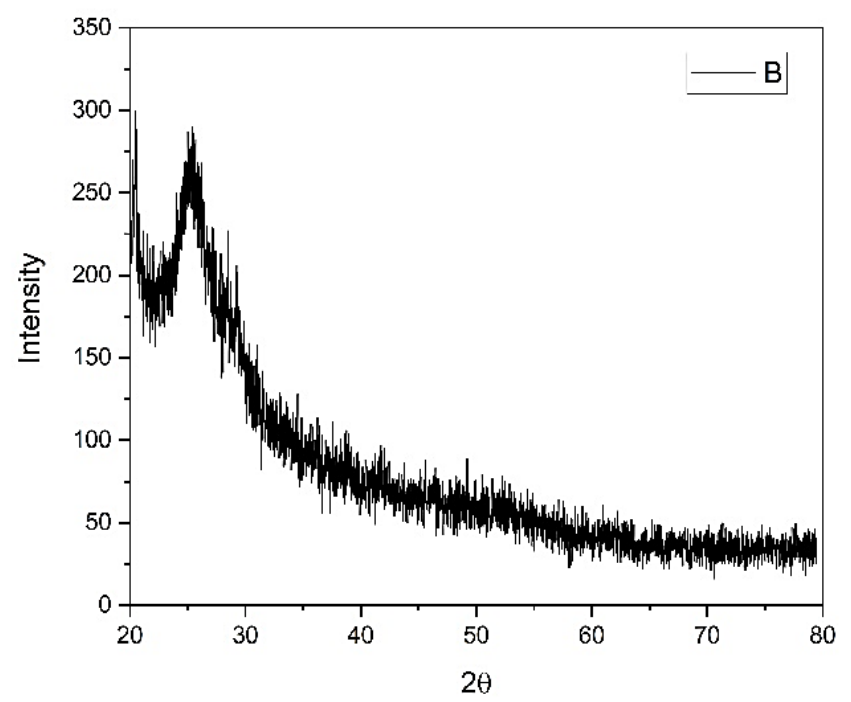

Fig. 3 X-Ray Diffraction pattern of pure PANI.

The average particle size of $\mathrm{CuO}$, PANI, and composites of PANI-CuO was calculated by the Debye Scherrer formula given by the following equation.

$$
D=\frac{0.9 \lambda}{\beta \cos \theta}
$$

where $\mathrm{D}$ is the average crystallite size of the powdered particles, $\lambda=1.54 \AA$ is the wavelength of $\mathrm{CuK} \alpha, \beta$ is full width at half maximum (FWHM) of the intensity of major peak, $\theta$ is the angular position of the peak (Bragg angle). ${ }^{[22]}$ The crystallite size of the $\mathrm{CuO}$ nanoparticle and pure PANI is found to be equal to $50.13 \mathrm{~nm}$ and $62 \mathrm{~nm}$, respectively. The average crystallite size of the nanocomposites of PANI/CuO is found to be $24.19 \mathrm{~nm}$. The size of these particles confirms the formation of $\mathrm{CuO}$ dispersed in PANI nanocomposite and indicates the increase in the crystallinity of nanocomposites.

\subsection{Fourier transform infrared spectroscopy}

The FTIR spectra of $\mathrm{CuO}$ nanoparticles and PANI-CuO nanocomposites are exhibited in Figs. 4 and 5 respectively.

In Fig. 4 two vibrational bands at $668.35 \mathrm{~cm}^{-1}$ and $772.50 \mathrm{~cm}^{-1}$ and one stretching band at $1339.59 \mathrm{~cm}^{-1}$ attribute characteristic bands of $\mathrm{Cu}(\mathrm{II}) \mathrm{O}$ nanoparticles. One other band at $1558.51 \mathrm{~cm}^{-1}$ shows the $\mathrm{Cu}-\mathrm{O}$ symmetrical stretching. Peaks obtained in the range of $500-700 \mathrm{~cm}^{-1}$ confirm the synthesis of copper oxide.

The FTIR spectra of PANI-CuO nanocomposites (Fig. 5), exhibit some shifting in the wavenumbers and also show some remarkable changes in the intensity of peaks when compared with the FTIR of pure PANI. ${ }^{[23]}$ This variation is due to the loss in conjugation and molecular order after the reformation of PANI with $\mathrm{CuO}$. The bands at $1557.79 \mathrm{~cm}^{-1}$ and $1491.00 \mathrm{~cm}^{-1}$ are assigned to $\mathrm{C}=\mathrm{N}$ and $\mathrm{C}=\mathrm{C}$ stretching modes of vibration 
for the quinonoid and benzenoid units of PANI, respectively. The peak at $1295.22 \mathrm{~cm}^{-1}$ attributes to the $\mathrm{C}-\mathrm{H}$ stretching mode of the benzenoid ring. The region of bands 477.39-844.84 $\mathrm{cm}^{-1}$ confirms the presence of $\mathrm{CuO}$ in the nanocomposite. The shifting in characteristic peaks of $\mathrm{CuO}$ indicates some interaction between $\mathrm{CuO}$ nanoparticles and PANI.

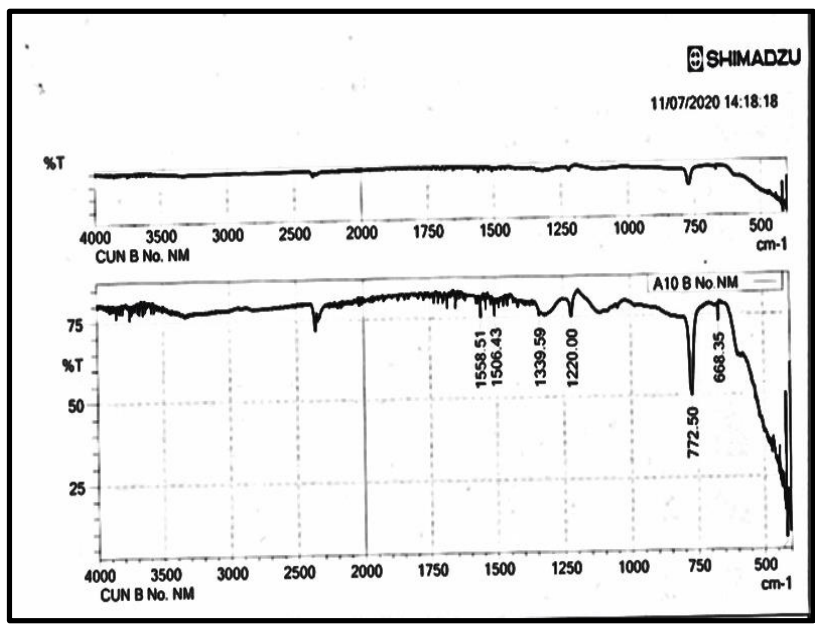

Fig. 4 FTIR spectrum of $\mathrm{CuO}$ nanoparticles.

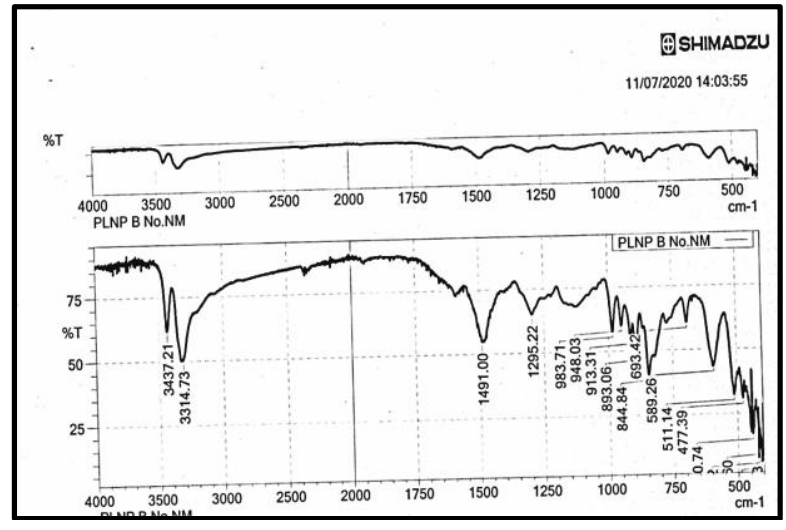

Fig. 5 FTIR spectrum of PANI-CuO nanocomposites.

\subsection{UV-Vis spectrometry}

UV Visible absorption spectra of $\mathrm{CuO}$ nanoparticles and PANI-CuO nanocomposites were recorded at room temperature using $\mathrm{NH} 4 \mathrm{Cl}$ and $\mathrm{N}, \mathrm{N}$-Dimethyl formamide as the solvents, respectively. Figs. 6 and 7 indicate the UVVisible spectra of $\mathrm{CuO}$ nanoparticles and PANI-CuO nanocomposite, respectively. The UV-Vis spectra of cupric oxide nanoparticles (Fig. 8) represent a strong absorption peak at the wavelength $218 \mathrm{~nm}$ which confirms the presence of $\mathrm{CuO}$ nanoparticles. ${ }^{[24]}$

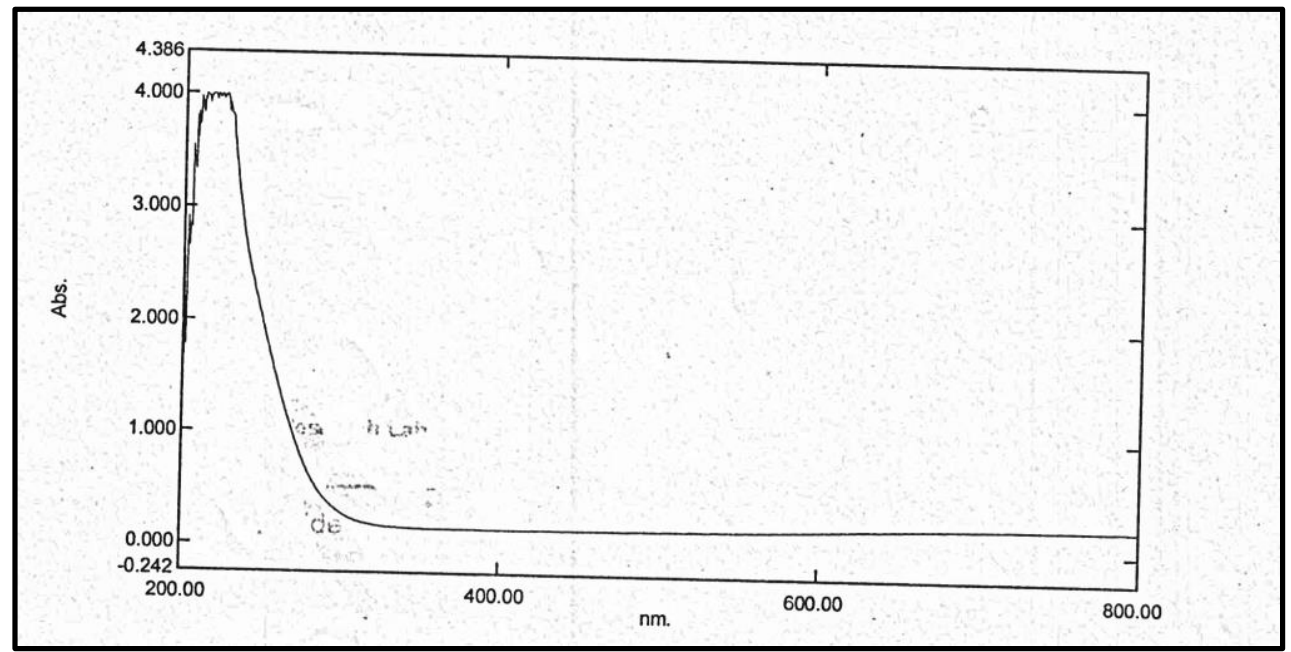

Fig. 6 UV-Vis absorption spectrum of $\mathrm{CuO}$ nanoparticles.

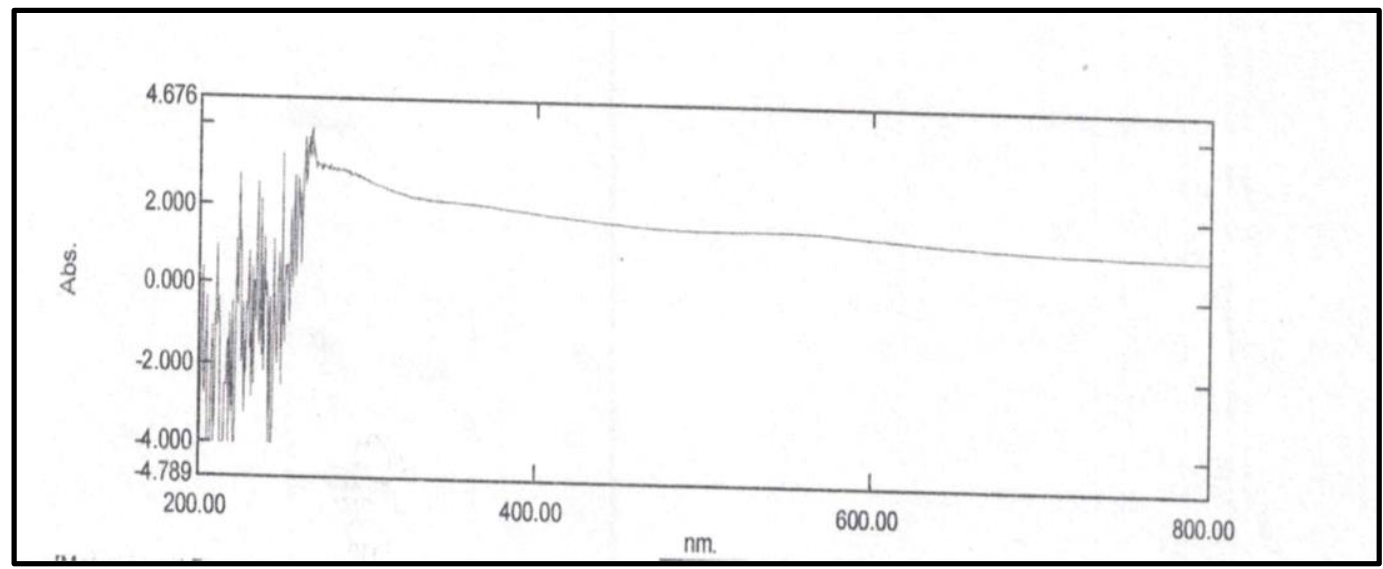

Fig. 7 UV-Vis absorption spectrum of PANi-CuO nanocomposites. 
The UV-Vis Spectra of PANI-CuO nanocomposites in Fig. 9 represents $\lambda_{\max }$ at $266.50 \mathrm{~nm}$ which is due to the $\pi-\pi^{*}$ transition of the benzenoid ring. The peak observed at 539.50 $\mathrm{nm}$ (in the range of around $520-655 \mathrm{~nm}$ ) is due to the interaction between $\mathrm{CuO}$ and the quinonoid ring of PANI. ${ }^{[2]}$

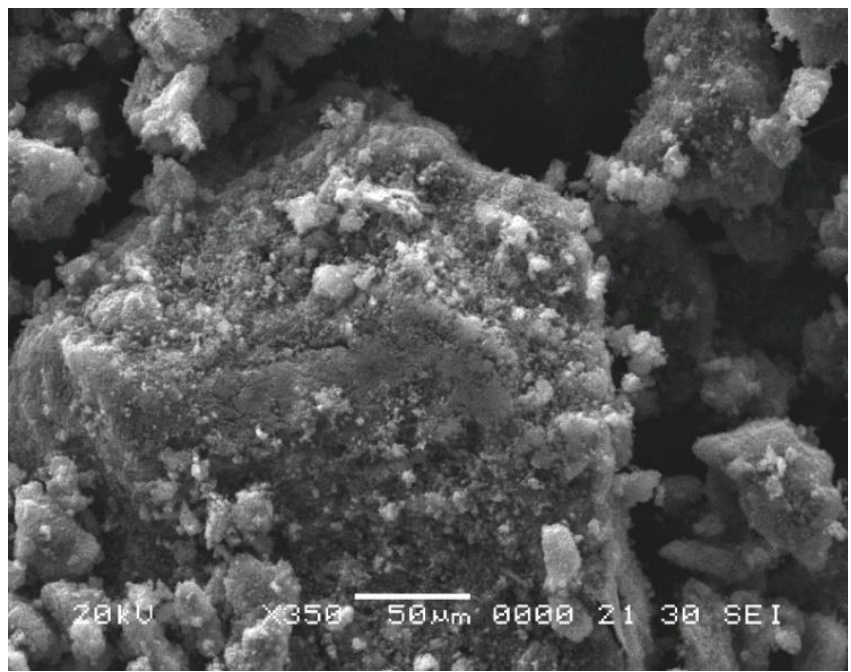

Fig. 8 SEM image of $\mathrm{CuO}$ nanoparticles.

\subsection{Scanning electron microscopy (SEM) with energy dispersive X-ray spectroscopy (EDAX)}

The surface morphology of $\mathrm{CuO}$ nanoparticles and PANI-CuO nanocomposite were exhibited in Figs. 8 and 9, respectively. The fine, granular, and spherical-shaped particles are visible in the SEM image (Fig. 8) of $\mathrm{CuO}$ nanoparticles. Some aggregation is also observed due to the aggregation of particles during washing. The SEM image of the nanocomposite shown in Fig. 9 depicted the strong effect of the incorporation of $\mathrm{CuO}$ particles on the morphology of the PANI chain. It is observed that the crystallinity decreases in PANI-CuO nanocomposites as compared to $\mathrm{CuO}$ nanoparticles. This is due to the amorphous nature of PANI. Some smooth solid blocks are visible in the SEM image of PANI-CuO nanocomposites because of the presence of oxide particles, which increases the crystalline nature of synthesized materials.

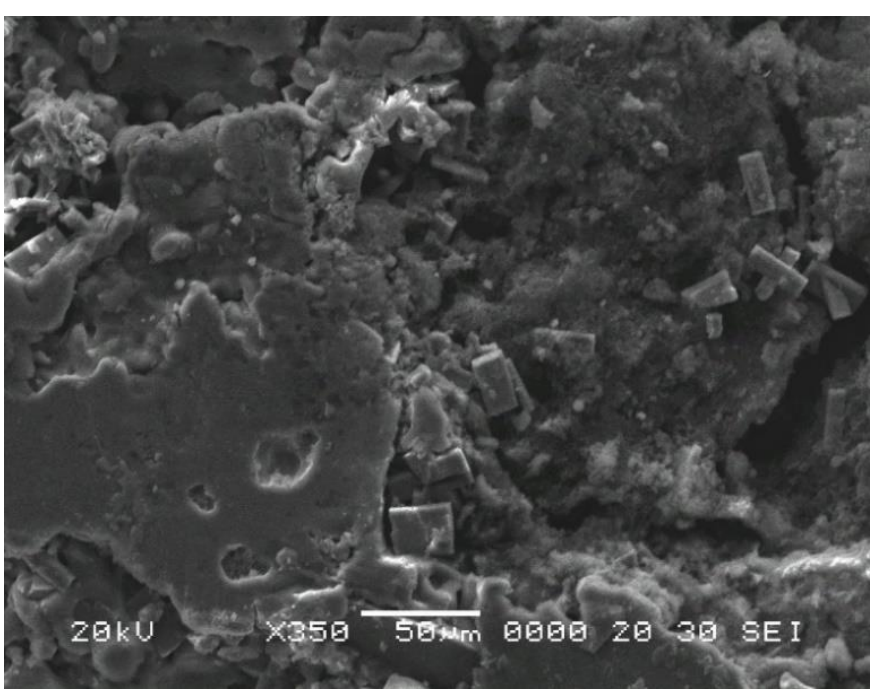

Fig. 9 SEM image of PANI - CuO nanocomposite.

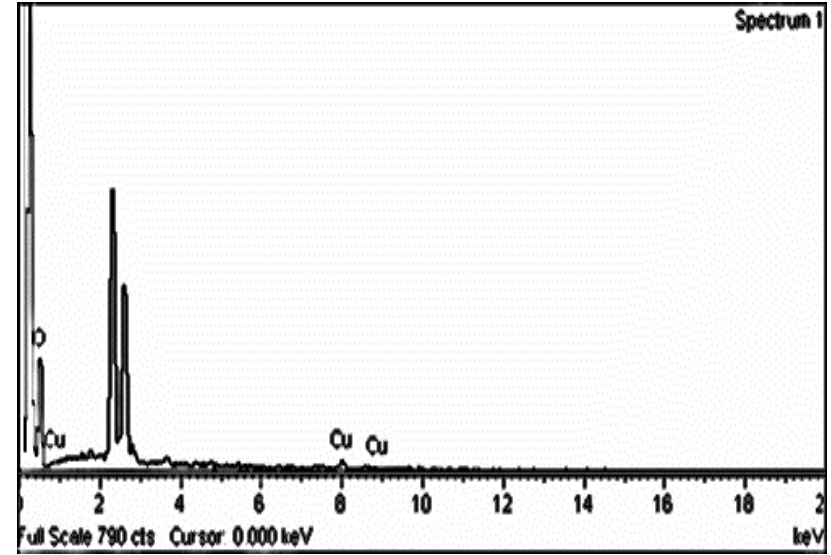

Fig. 10 Energy Dispersive X-ray Spectra of $\mathrm{CuO}$ nanoparticles.

The EDAX spectrum shown in Fig. 10 confirms the formation of $\mathrm{CuO}$ nanoparticles without impurities. The spectrum reveals that the synthesized nanoparticles are pure and stoichiometric.

\subsection{Electrical Examination}

The electrical examination is a very important property to exploring applications of synthesized materials in electrical devices. The DC conductivity of synthesized materials was measured by using a four-probe conductivity measurement. The formula for calculating DC conductivity is $\sigma=\mathrm{d} / \mathrm{A}(\mathrm{I} / \mathrm{V})$, where $\sigma=$ conductivity, $d=$ thickness of the sample, $A=$ area of the electrode, $\mathrm{V}=$ applied voltage, and $\mathrm{I}=$ measured current.

The conductivity of pure PANI and PANI-CuO nanocomposites were found to be $1.6 \times 104 \mathrm{~S} \mathrm{~cm}^{-1}$ and $3.1 \times$ $104 \mathrm{~S} \mathrm{~cm}^{-1}$, respectively. The above values verified that the conductivity increases when the pure PANI is transformed into nanocomposites with $\mathrm{CuO}$ particles since the migration of charge carriers improved in the PANI-CuO nanocomposite.

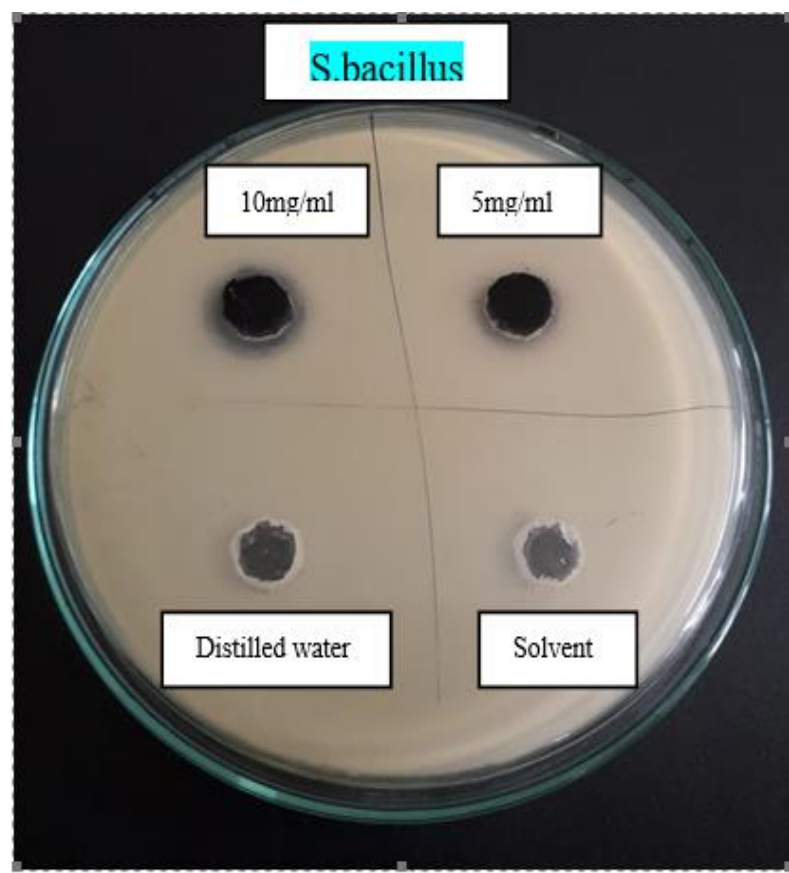

Fig. 11 Antimicrobial activity of PANI copper oxide nanocomposites against $\mathrm{S}$. bacillus. 
Table 1. Comparison in the zones of inhibition between synthesized PANI-CuO nanocomposites and different reported materials having a concentration of $10 \mathrm{mg} / \mathrm{ml}$ against Bacillus subtilis and Escherichia coli.

\begin{tabular}{ccccc}
\hline Bacteria & Material & Conductivity & Inhibition zone $(\mathrm{mm})$ & References \\
Bacillus subtilis & PANI & $1.6 \times 10^{4} \mathrm{~S}$ & 8 & {$[26]$} \\
(Gram+ve) & PANI-CuO Nanocomposites & $3.1 \times 10^{4} \mathrm{~S}$ & 13 & Present work \\
Escherichia coli & CuO nanoparticles & & 14 & {$[28]$} \\
(Gram-ve) & PANI & & 9 & {$[26]$} \\
& PANI-CuO Nanocomposites & & 19 & Present work \\
\hline
\end{tabular}

\subsection{Antimicrobial Activity}

The evaluation of antimicrobial activity for prepared nanocomposites were performed using a Kirby-Bauer disc diffusion test method. The discs of approximately $6 \mathrm{~mm}$ in diameter were fabricated and placed in a Petri dish. The Petri dishes were sterilized under suitable conditions in the autoclave and then the diameters of inhibition growth zones were assessed. ${ }^{[28]}$ The bacteria were incubated for $24 \mathrm{~h}$ at $37^{\circ} \mathrm{C}$ on nutrient agar. The synthesized material was placed over the nutrient agar plates in concentrations of $5 \mathrm{mg} / \mathrm{ml}$ and $10 \mathrm{mg} / \mathrm{ml}$. Figs. 11 and 12 exhibit the antimicrobial activity of synthesized PANI-CuO nanocomposites against Bacillus subtilis and Escherichia coli. In the case of Bacillus subtilis, the zone of inhibition for $10 \mathrm{mg} / \mathrm{ml}$ and $5 \mathrm{mg} / \mathrm{ml}$ are $13 \mathrm{~mm}$ and $10 \mathrm{~mm}$, respectively. For Escherichia coli, the zone of inhibition for $10 \mathrm{mg} / \mathrm{ml}$ and $5 \mathrm{mg} / \mathrm{ml}$ are $19 \mathrm{~mm}$ and $17 \mathrm{~mm}$, respectively. The average zone of inhibition against pathogenic bacteria confirms the antibacterial property of synthesized conducting polymer. Table 1 reported the comparison in the antimicrobial activity between the previously reported materials and synthesized nanocomposite.

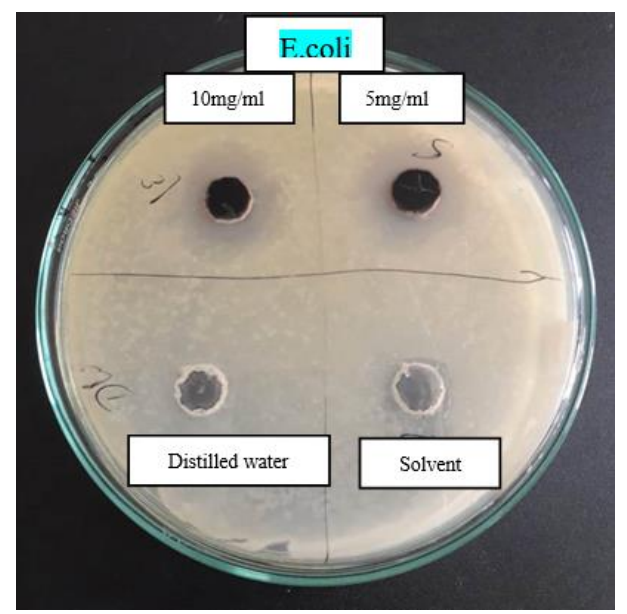

Fig. 12 Antimicrobial activity of PANI copper oxide nanocomposites against E. coli.

\section{Conclusion}

The peaks obtained in the XRD investigation are in good agreement with the reported values. The average particle size of $\mathrm{CuO}$, pure PANI, and PANI-CuO nanocomposite was found to be equal to $50.13 \mathrm{~nm}, 62 \mathrm{~nm}$, and $24.19 \mathrm{~nm}$, respectively. The characteristic peaks of FTIR and UV-Vis spectroscopy confirm the successful synthesis of materials. It is observed in the morphological studies (SEM) of $\mathrm{CuO}$ and PANI-CuO that because of the amorphous nature of PANI, the crystallinity is decreases in PANI-CuO nanocomposites as compared to $\mathrm{CuO}$ nanoparticles.

From the four-probe conductivity measurements, it is clear that the conductivity increases when the pure PANI is converted into nanocomposites with $\mathrm{CuO}$ particles. We also conclude that the increase in conductivity of the material results positive effect in killing the microbes such as $\mathrm{S}$. Bacillus and E. Coli.

\section{Acknowledgment}

We acknowledge Shri Vaishnav Vidyapeeth Vishwavidyalaya, Indore, for providing laboratory facilities. We are grateful to UGC-DAE Consortium for Scientific Research Center, Indore to provide analytical facilities.

\section{Supporting Information}

Not Applicable.

\section{Conflict of Interest}

There is no conflict of interest.

\section{References}

[1] M. Gerard, A. Chaubey, B. D. Malhotra, Biosensors \& Bioelectronics, 2002, 17, 345-359, doi: 10.1016/s09565663(01)00312-8.

[2] S. P. Ashokkumar, L. Yesappa, H. Vijeth, M. Niranjana, H. Devendrappa, AIP Conference Proceedings, 2018, 1953, 030222, doi: $10.1063 / 1.5032557$.

[3] S. J. Shivhare, P. K. Loharkar, S. Vyas, Asian Journal of Materials Chemistry, 2019, 4, 14-17, doi: 10.14233/ajmc.2019.ajmc-p73.

[4] D Majumdar, Innovative Energy \& Research, 2016, 5, 1-16, doi: 10.4172/2576-1463.1000145.

[5] S. J. Shivhare, P. K. Loharkar, S. Vyas, M. Sharma, V. S. Bagal, Advanced Materials Letters, 2020, 11, 1-9, doi: 10.5185/amlett.2020.111571.

[6] L. I. Nadaf, K. S. Venkates, Material Science Research India, 2015, 12, 108-111, doi: 10.13005/msri/120204.

[7] H. Qamar, S. Rehman, D. K. Chauhan, A. K. Tiwari, V. Upmanyu, International Journal of Nanomedicine, 2020, 15, 2541-2553, doi: 10.2147/ijn.s240232.

[8] A. Mittiga, E. Salza, F. Sarto, M. Tucci, R. Vasanthi, Applied Physics Letters, 2006, 88, 163502, doi: 10.1063/1.2194315. 
[9] S. Singh, M. Kalhan, J. S. Malik, A. Jangra, N. Sharma, S. Singh, International Journal of Advances in Medicine, 2018, 5 624-629, doi: 10.18203/2349-3933.ijam20182113.

[10] S. P. Ashokkumar, H. Vijeth, L. Yesappa, M. Niranjana, M. Vandana, H. Devendrappa, Inorganic Chemistry Communications, 2020, 115, 107865, doi: 10.1016/j.inoche.2020.107865.

[11] P. Singh and S. K. Shukla, Surfaces and Interfaces, 2020, 18, 100410, doi: 10.1016/j.surfin.2019.100410.

[12] M. B. Gholivand, H. Heydari, A. Abdolmaleki, H. Hosseini, Materials Science in Semiconductor Processing, 2015, 30, 157 161, doi: 10.1016/j.mssp.2014.09.047.

[13] A. Yadav, H. Kumar, R. Sharma, R. Kumari, Colloid and Interface Science Communications, 2021, 40, 100339, doi: 10.1016/j.colcom.2020.100339.

[14] L. Tmayo, M. Azocar, Materials Science and Engineering: C, 2016, 69, 1391-1409, doi: 10.1016/j.msec.2016.08.041.

[15] D. Das, B. C. Nath, P. Phukon, S. K. Dolui, Colloids and Surfaces B: Biointerfaces, 2013, 101, 430-433, doi: 10.1016/j.colsurfb.2012.07.002.

[16] A. Azam, A.S. Ahmed, M. Oves, M.S. Khan, S.S. Habib, A. Memic, International Journal of Nanomedicine, 2012, 7, 60036009, doi: 10.2147/IJN.S35347.

[17] Y. C. Xie, D. M. Yu, N. N. Zhang, H. L. Liang, PolymerPlastics Technology and Engineering, 2011, 50, 168-172, doi: 10.1080/03602559.

[18] B. Vellaichamy, P. Periakaruppan, Industrial \& Engineering Chemistry Research, 2018, 57, 6684-6695, doi: 10.1021/acs.iecr.8b01098.

[19] Z. Zhou, X. Zhang, C. Lu, L. Lan, G. Yuan, RSC Advances, 2014, 4, 8966, doi: 10.1039/c3ra46441e.

[20] L. Ge, C. Han, J. Liu, Journal of Materials Chemistry, 2012, 22, 11843-11850, doi: 10.1039/C2JM16241E.

[21] H. Gulce, V. Eskizeybek, B. Haspulat, F. Sari, A. Gulce, A. Avci, Industrial \& Engineering Chemistry Research, 2013, 52, 10924, doi: 10.1021/ie401389e.

[22] S. M. Ambalagi, M. Devendrappa, S. Nagaraja, B. Sannakki, IOP Conference Series: Materials Science and Engineering, 2018, 310, 012081, doi: 10.1088/1757-899x/310/1/012081.

[23] S. Ashokan, P. Jayamurugan, V. Ponnuswamy, Polymer Science, Series $B, \quad 2019, \quad 61, \quad 86-97, \quad$ doi: 10.1134/S1560090419010020.

[24] N. R. Dhineshbabu, V. Rajendran, N. Nithyavathy, R. Vetumperumal, Applied Nanoscience, 2016, 6, 933-939, doi: 10.1007/s13204-015-0499-2.

[25] L. Lu, T. Zheng, Q. Wu, A. M. Schneider, D. Zhao, L. Yu, Chemical Reviews, 2015, 115, 12666-12731, doi: 10.1021/acs.chemrev.5b00098.

[27] S. Sultana, Rafiuddin, M. Z. Khan, K. Umar, M. Muneer, Journal of Materials Science \& Technology, 2013, 29, 795-800, doi: 10.1016/j.jmst.2013.06.001.

[28] A. Azam, A. S. Ahmed, M. Oves, M. S. Khan, A. Memic, International journal of nanomedicine, 2012, 7, 3527-3535, doi: 10.2147/IJN.S29020.

[26] M. Balouiri, M. Sadiki, S. K. Ibnsouda, Journal of
Pharmaceutical Analysis, 2016, 6, 277, doi: 10.1016/j.jpha.2015.11.005.

\section{Author information}

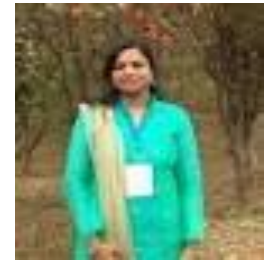

Supriya Vyas is working as Assistant Professor in Department of Chemistry, Shri Vaishnav Vidyapeeth Vishwavidyalay Indore (M.P.) from 2013. She has more than 13 years of teaching experience. She received her M.Sc. degree in Chemistry from Govt. Holkar Science College, Indore in 2007 and M.Phil. in chemistry in the year 2012. Her research interests include Nanomaterials, conducting polymers, energy storage devices, biodiesel etc. She has published her work in reputed journals.

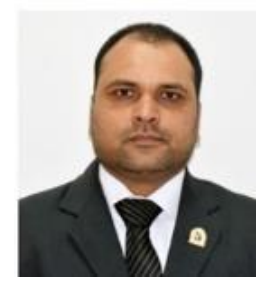

Dr. Sugam J Shivhare received the M. Sc. (Applied Chemistry) with specialization in organic chemistry from School of Chemical Sciences, Devi Ahaliya Vishwavidyalaya, Indore, Madhya Pradesh, India in 2001. He received his doctorate in chemistry on Polarographic and Voltammetric Study on some Heterocyclic Compounds containing Nitrogen with life Essential Elements" from Govt. Holkar Sc. College, Devi Ahaliya Vishwavidyalaya, Indore, Madhya Pradesh, India in 2014. He is currently working as Assistant Professor in SVKM's NMIMS University, Shirpur Campus, Disttrict:Dhule, Maharashtra, India. He has authored or co-authored 20 publications in various reputed journals. His research interest includes synthesis of various nanostructures for the applications of supercapacitors and batteries.

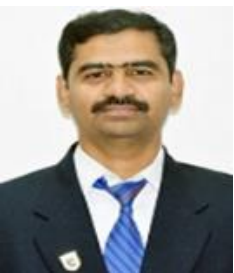

Dr. Vivekanand $S$. Bagal received received the M. Sc. (Physics) with specialization in material science from the department of Physics, School of Physical Sciences, Kavayitri Bahinabai Chaudhari North Maharashtra University, Jalgaon, Maharashtra, India, in 2006. He also Ph. D. degree in Physics from the department of Physics, School of Physical Sciences, Kavayitri Bahinabai Chaudhari North Maharashtra University, Jalgaon, Maharashtra, India, in 2019. He is currently working as Assistant Professor in SVKM's NMIMS University, Shirpur Campus, Disttrict: Dhule, Maharashtra, India. He has authored or co-authored 18 publications in various reputed journals. His research interest includes synthesis of various nanostructures and nanoheterostructures for the applications of field emission and supercapacitors.

Publisher's Note Engineered Science Publisher remains neutral with regard to jurisdictional claims in published maps and institutional affiliations. 